\title{
The thermo-oxidative degradation of poly(4-methylstyrene) and its relationship to flammability
}

S. McCreath ${ }^{\mathrm{a}}$, J. Lewicki ${ }^{\mathrm{b}}$, J. J. Liggat ${ }^{\mathrm{a}}$, C. Lithgow ${ }^{\mathrm{a}}$, L. McCulloch ${ }^{\mathrm{a}}$, K. Miller ${ }^{\mathrm{a}}$ A. Witkowskic

aWestCHEM, Department of Pure and Applied Chemistry, University of Strathclyde, Glasgow, Scotland

${ }^{b}$ Chemical Sciences Division, Forensics and Assessments Support, Lawrence Livermore National Laboratory, Livermore, USA

${ }^{c}$ School of Forensic and Investigative Sciences, University of Central Lancashire, Preston, $U K$

*Corresponding author: email j.j.liggat@strath.ac.uk, phone +44 (0) 1415484351

\begin{abstract}
Polystyrene and poly(4-methylstyrene) have very similar chemical structures with the only differences being the para methyl group of poly(4-methylstyrene). This methyl group is susceptible to oxidation at elevated temperatures. Here we demonstrate that it is possible to introduce oxidative cross-links to poly(4-methylstyrene), via the para methyl group, by thermal oxidative treatment at $230^{\circ} \mathrm{C}, 250^{\circ} \mathrm{C}$ and $270^{\circ} \mathrm{C}$ in the absence of catalyst, leading to a material with markedly modified thermal degradation chemistry. Thermal gravimetric analysis and differential scanning calorimetry were used to characterise and compare untreated and post-oxidised materials and established that as the temperature of pre-treatment was increased, the subsequent thermal stability of the material increased. FTIR, NMR and microanalysis indicated that after the thermal oxidative pre-treatment ether cross-links are present alongside new oxygen containing functional groups such as aldehydes, carboxylic acids and hydroxyl groups. Finally, data obtained from pyrolysis combustion flow calorimetry confirmed that as the number of oxidative cross-links increase, a reduction in the polymer's flammability as assessed by heat release data is observed.
\end{abstract}

Keywords: Thermo-oxidation, Thermogravimetry, Pyrolysis combustion flow-calorimetry. 


\subsection{Introduction}

The high flammability of polymer materials is one of their main shortcomings and as a consequence developing routes to reduce this flammability is a very active area of polymer research. Polystyrene, in particular, has a very high flammability and with its high aromatic content is particularly problematic in fires as it generates large quantities of disorientating black smoke. Despite this well-known problem polystyrene is still one of the big four commercially produced and used polymers today.

The degradation of polystyrene has been extensively studied, and has been shown to be a radical process which resulting from random chain scission along the polymer backbone and at weak points situated at tertiary hydrogen atoms. ${ }^{1-3}$ In the absence of oxygen degradation through chain scission occurs within the temperature range of $200-300^{\circ} \mathrm{C}$ and as a result the molecular mass of the polymer falls. ${ }^{4}$ This type of degradation occurs without the liberation of any low molecular mass volatile molecules. Above $300^{\circ} \mathrm{C}$ depolymerisation to monomers, dimers and trimers is observed followed by their further breakdown. The degradation profile obtained greatly depends on a variety of factors such as the type of polymerisation process, the molecular mass of the polystyrene and the degradation environment. ${ }^{4-6}$ As it is the low molecular mass volatile products that actually burn, and not the bulk polymer itself, understanding the mechanism of the degradation processes is key to determining suitable methods for flammability reduction. In a fire at least part of the degradation chemistry is oxidative. The nature of this oxidative chemistry is largely independent of the nature of the organic substrate and Benson and Nangia were able to detail the temperature dependence of different oxidative free-radical mechanisms involved. ${ }^{7}$ The first region discussed was the chemistry at temperatures below $200^{\circ} \mathrm{C}$ and the authors described this as the region were "easily oxidized" organic compound will undergo oxidation via a free radical process. ${ }^{7}$ They also proposed the following chain cycle:

$$
\begin{aligned}
\mathrm{R} \cdot+\mathrm{O}_{2} & \stackrel{1}{\rightleftharpoons} \mathrm{RO}_{2} \cdot \\
\mathrm{RO}_{2} \cdot+\mathrm{RH} & \stackrel{2}{\rightleftharpoons} \mathrm{RO}_{2} \mathrm{H}+\mathrm{R} \cdot
\end{aligned}
$$

Giving the net reaction:

$$
\mathrm{RH}+\mathrm{O}_{2} \longrightarrow \mathrm{RO}_{2} \mathrm{H}+18-24 \mathrm{kcal}
$$


Species that contain a weak $\mathrm{C}-\mathrm{H}$ bond are oxidised within this region. Functional groups such as aldehydic $\mathrm{C}-\mathrm{H}$ as well as $\mathrm{C}-\mathrm{H}$ that occupy a benzylic or tertiary position (as in polystyrene) are oxidised within this region. It was noted that such reactions are slow and that transition ' 2 ' has a moderately high activation energy. ${ }^{7}$ This is effectively the peroxidation model derived originally by Bolland and Gee. ${ }^{8,9}$

Next the authors discussed the chemistry for radical mechanisms that occur above $250^{\circ} \mathrm{C}$ and they commented that the mechanism appeared to change: ${ }^{10}$

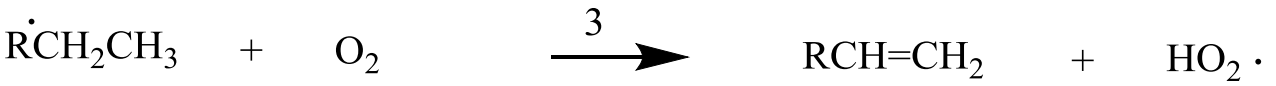

$$
\begin{aligned}
& \mathrm{HO}_{2} \cdot+\mathrm{RCH}_{2} \mathrm{CH}_{3} \stackrel{4}{\longrightarrow}+\mathrm{HO}_{2} \mathrm{H}+\mathrm{RCH}_{2} \mathrm{CH}_{3}
\end{aligned}
$$

Giving the net reaction:

$\mathrm{O}_{2}+\mathrm{RCH}_{2} \mathrm{CH}_{3} \longrightarrow \mathrm{RCH} \mathrm{CH}_{2}+\mathrm{H}_{2} \mathrm{O}_{2}+2 \mathrm{kcal}$

Reactions within the lower temperature regime are fairly exothermic in nature and could possibly display autocatalytic character. The higher temperature mechanism has a small free energy change and is almost thermo-neutral in comparison. Furthermore, the authors alluded to the fact that both systems are prone to having secondary reaction which tend to yield products higher in reactivity than the reaction starting materials. This adds further complexity to the oxidative chemistry occurring and can obscure the primary reaction.

A variety of methods have been employed in trying to reduce the flammability of polystyrene. Bromination was one of the earliest methods of stabilisation, with brominecontaining polystyrenes displaying very similar mechanisms of degradation to polystyrene. This suggests that the bromination had little effect on the condensed phase chemistry, with the bromine acting in the gas phase $e^{4,11,12}$ However, work by McNeill et al. established that the mode of polystyrene bromination influenced its degradation, with differences being observed between main chain and ring brominated polystyrenes. ${ }^{13}$ Such strategies that use halogens to fire retard polystyrene are under increasing pressure due to environmental concerns that the use of halogens carry. Reducing volatile yield through cross-linked char formation is another strategy, although polystyrene, even under oxidative conditions largely 
degrades via depolymerisation with little intrinsic cross-linking. Whilst oxidative dehydrogenation of tertiary benzylic hydrogen does occur, this leads to chain unsaturation weakens the beta $\mathrm{C}-\mathrm{C}$ chain bond. Thus, further dehydrogenation which would lead to polyene structure capable evolving to aromatic char (as per PVC) is limited by chain scission of allylic chain bonds, particularly under dynamic heating. However, polystyrene has also been modifiedthrough synthesis of alkyne groups to the para-position of the aromatic ring, with these polymers showing high char yields due to a high degree of cross-linking. ${ }^{14}$ Crosslinking has also been introduced using Friedel-Crafts chemistry. ${ }^{15-17}$ The use of nano-clay materials has also been used in the stabilisation of polystyrene with a proven increase in thermal stabilisation. The degradation products are of the same nature as those obtained by other stabilisation methods, giving monomer, dimer and higher oligomers complete with their further breakdown products. Interestingly the degradation pathway was altered due to the physical effects on the polymer system due to the clay additive. ${ }^{18-21}$ Phosphonated polystyrenes have also shown a reduction in flammability when compared to polystyrene. ${ }^{22,23}$ The increased availability of poly(4-methylstyrene) has led to its increased use in, for example, unsaturated polyester-styrene coating systems. Anecdotal evidence suggests that poly(4-methylstyrene) is less flammable than polystyrene due to the ready formation of oxidative cross-links, although there is little experimental evidence to support this claim. That such cross-linking is not observed in polystyrene indicates that there is a cross-linking mechanism is specific to poly(4-methylstyrene) and thus cannot operate solely through the readily abstractable benzylic hydrogen. Here we demonstrate that it is possible to introduce oxidative cross-links to poly(4-methylstyrene), via the para methyl group, by thermal oxidative treatment at $230^{\circ} \mathrm{C}, 250^{\circ} \mathrm{C}$ and $270^{\circ} \mathrm{C}$ in the absence of catalyst, leading to a material with markedly modified thermal degradation chemistry.

\subsection{Experimental}

\subsection{Materials}

Poly(4-methylstyrene) powder (Mw 70000) was purchased from Acros Organics and polystyrene powder (Mw 195900) was purchased from Polymer Laboratories. Each material was purified by dissolving in dichloromethane (DCM) and precipitating in a ten-fold excess of methanol. The precipitated polymer was collected by vacuum filtration and dried at $60^{\circ} \mathrm{C}$ in a vacuum oven. DCM and methanol reagent grade solvents were purchased from SigmaAldrich, with both used as-received. 


\subsection{Pre-oxidised material formation}

Production of the pre-oxidised material was performed by casting a thin film of the polymer onto the base of glass vial from $4 \mathrm{ml}$ of a $0.25 \mathrm{~g} \mathrm{~mL}^{-1}$ solution of purified polymer in DCM. The thin polymer film was then heated isothermally in air at $230^{\circ} \mathrm{C}, 250^{\circ} \mathrm{C}$ or $270^{\circ} \mathrm{C}$ for 60 minutes. The material was then allowed to cool to room temperature and extracted with DCM to remove any soluble material. The insoluble material was then dried in a vacuum oven at $80^{\circ} \mathrm{C}$ for 48 hours. The isolated material was now ready for analysis and was used without any further purification.

\subsection{Thermal Gravimetric Analysis (TGA)}

All TGA experiments were carried out using a Perkin Elmer TGA7 thermal gravimetric analyser with 8-10 $\mathrm{mg}$ of powdered samples being analysed. The system was heated isothermally at $40^{\circ} \mathrm{C}$ for five minutes at the beginning of each experiment. After this initial period, the sample was heated at a rate of $10^{\circ} \mathrm{C} \mathrm{min}^{-1}$ from $40^{\circ} \mathrm{C}$ to $850^{\circ} \mathrm{C}$ under a flow of 30 $\mathrm{ml} \mathrm{min}{ }^{-1}$ of helium or air as appropriate. The mass loss of the sample was monitored as a function of temperature. From this mass loss the first derivative of the mass loss curve was calculated again as a function of temperature. The onset of degradation temperature was calculated from the TGA curve as the temperature at which the sample has lost $5 \%$ of its original weight.

\subsection{Thermal Volatilisation Analysis (TVA)}

All TVA analysis was carried out on a built in-house TVA line, which was based upon the apparatus described by McNeill et al.. ${ }^{24-26}$ The technique is carried out under a vacuum of $10^{-4}$ torr which is achieved by continuously pumping the system using a two-stage rotary pump and oil diffusion pump system. The TVA techniques set-up consists of a sample that is heated using a programmable tube furnace which is connected in series with a primary liquid nitrogen sub-ambient cold trap. Collection of volatile products is performed in two stages: immediately above the tube furnace a cooled water jacket or 'cold ring' is used to condense any high boiling point materials that would condense at ambient temperature and the primary liquid nitrogen sub-ambient cold trap which collects the volatile products with low boiling points which will not condense at ambient temperature. Between the furnace and the primary cold trap a linear response Pirani gauge is positioned which records the total volatile products evolved (both condensable and non-condensable species) from the sample as a function of pressure versus temperature/time. At the exit of the primary cold trap a second Pirani gauge is positioned to monitor the evolution of any non-condensable volatile species as a function 
of pressure versus temperature/time. These low boiling point species can then be differentially distilled into separate secondary cold traps by distilling the products off by slow heating of the primary sub-ambient cold trap up to ambient temperature. The isolated volatile species are located in separate fractions within gas-phase cells making them analysable by FTIR and GC-MS. The process of sub-ambient distillation is performed by heating the primary cold trap from $-196^{\circ} \mathrm{C}$ to ambient temperature with the volatile species separated into four major fractions. Each one of these fractions has a non-linear Pirani gauge at the entrance and exit of their secondary cold trap to monitor pressure changes as volatiles are collected in each fraction. The product stream is also continuously sampled between the primary and secondary cold traps using a 1-300 amu Hiden single quadrapole RGA mass spectrometer during both the degradation and sub-ambient distillation stages.

All TVA runs were conducted under high vacuum with $25 \mathrm{mg}$ of sample. Polystyrene and poly(4-methylstyrene) materials were heated from ambient temperature to $550^{\circ} \mathrm{C}$ at a rate of $10^{\circ} \mathrm{C} \min ^{-1}$.

\subsection{Fourier Transform Infra-red spectroscopy (FTIR)}

Analysis of the solid polystyrenes was carried out using an Agilent Technologies 4500 Series Portable FTIR Spherical Diamond attenuated total reflectance (ATR) in absorbance mode. For each material five replicate samples were analysed, with each spectrum consisting of 128 scans at $8 \mathrm{~cm}^{-1}$ resolution. Spectral processing was carried out using LabCognitions panorama FTIR spectral processing software.

\subsection{Nuclear magnetic resonance spectroscopy (NMR)}

All ${ }^{1} \mathrm{H}$ solution state NMR analysis of the pre-oxidised sample were carried out on a Bruker Avance III NMR spectrometer operating at a $600 \mathrm{MHz}{ }^{1} \mathrm{H}$ Larmor frequency and using a Bruker 5mm PABBO broadband $-{ }^{1} \mathrm{H} / \mathrm{D}$ gradient probe.

For ${ }^{1} \mathrm{H}$ solution state experiments, solutions of pre-oxidised sample were prepared by dispersing a mass of finely powdered sample in an appropriate volume of $\mathrm{d}_{7}$ dimethylformamide, spiked with 0.03 wt. \% tetramethylsilane (TMS) to yield a $50 \mathrm{mg} \mathrm{mL}^{-1}$ mixture. This mixture was left for 48 hours at $40^{\circ} \mathrm{C}$ to ensure adequate swelling of the polymer in the DMF before transfer to a $600 \mathrm{MHz}$ Norell ${ }^{\mathrm{TM}} 5 \mathrm{~mm}$ NMR tube.

${ }^{1} \mathrm{H}$ spectra were obtained using a standard $1 \mathrm{D}$ sequence optimized for ${ }^{1} \mathrm{H}$ (Bruker ' $\mathrm{zg}$ ' pulse program), using a $90^{\circ}$ pulse length of $12 \mu$ s at 15.2 watts and a recycle delay of 60 seconds. 
64 Scans were collected with a spectral window of $20 \mathrm{ppm}$. All ${ }^{1} \mathrm{H}$ spectra were referenced to TMS at $0 \mathrm{ppm}$.

\subsection{Pyrolysis Combustion Flow Calorimetry (PCFC)}

PCFC is a non-flaming controlled pyrolysis technique that allows for the reproduction of both solid and gas phase product of flaming combustion separately. This is performed within an inert gas stream which is subsequently followed by high temperature oxidation of the pyrolysis products. The heat of combustion evolved by these products is measured using oxygen consumption calorimetry. ${ }^{27}$ Thus from calculating the maximum amount of heat released from the material, a good indication of its flammability can be obtained. Experiments were carried out in triplicate using $5 \mathrm{mg}$ samples on the Federal Aviation Administration's Pyrolysis Combustion Flow Calorimeter. Samples were heated at $60^{\circ} \mathrm{C}$ $\mathrm{min}^{-1}$ in a nitrogen stream of $80 \mathrm{~mL} \mathrm{~min}{ }^{-1}$ with the pyrolysis temperature taken to $900^{\circ} \mathrm{C}$. The volatile degradation products that now occupy the nitrogen stream were mixed with a $20 \mathrm{~mL}$ $\min ^{-1}$ stream of oxygen which was then passed into the combustion furnace set at $900^{\circ} \mathrm{C}$. Oxygen consumption calorimetry was used to determine the heat released.

\subsection{Elemental analysis}

All elemental analysis was carried out using a Perkin-Elmer 2400 series analyser.

\subsection{Results and Discussion}

\subsection{TVA}

When studying the degradation profile of a polymer, thermal volatilisation analysis is a very informative starting point as it allows characterisation of the volatile and non-volatile products produced during degradation. Although analysis is undertaken under high vacuum conditions, it allows access to the mechanisms that occur during degradation, which can assist with the interpretation of data obtained from subsequent oxidative analysis. Another application of the TVA technique is that it allows the comparison of polymers that have subtle differences in structure and degradation profile.

The degradation profile obtained from TVA for the polystyrene polymers, displays the rate of sample volatilisation as a function of furnace temperature/time, as shown in figure 1. Both polystyrene and poly(4-methylstyrene) show a single stage decomposition which is in 
agreement with previous literature, with the degradation occurring over a temperature range of $270-535^{\circ} \mathrm{C} .^{4}$ TVA data shows that there is a negligible difference in degradation profile between polystyrene (peak of volatilisation at $428^{\circ} \mathrm{C}$ ) and poly $(4-m e t h y l s t y r e n e)$ (peak of volatilisation at $420^{\circ} \mathrm{C}$ ) in a non-oxidative environment. Following the degradation stage of the TVA run, sub-ambient distillation was performed which allows separation of the major degradation products into fractions, as shown in figure 2. Polystyrene and poly(4methylstyrene) both show a single product peak. The only noticeable difference observed was the temperature at which the two products distilled from the sub-ambient trap, with the polystyrene degradation product evolving at a lower temperature than that from poly(4methylstyrene).

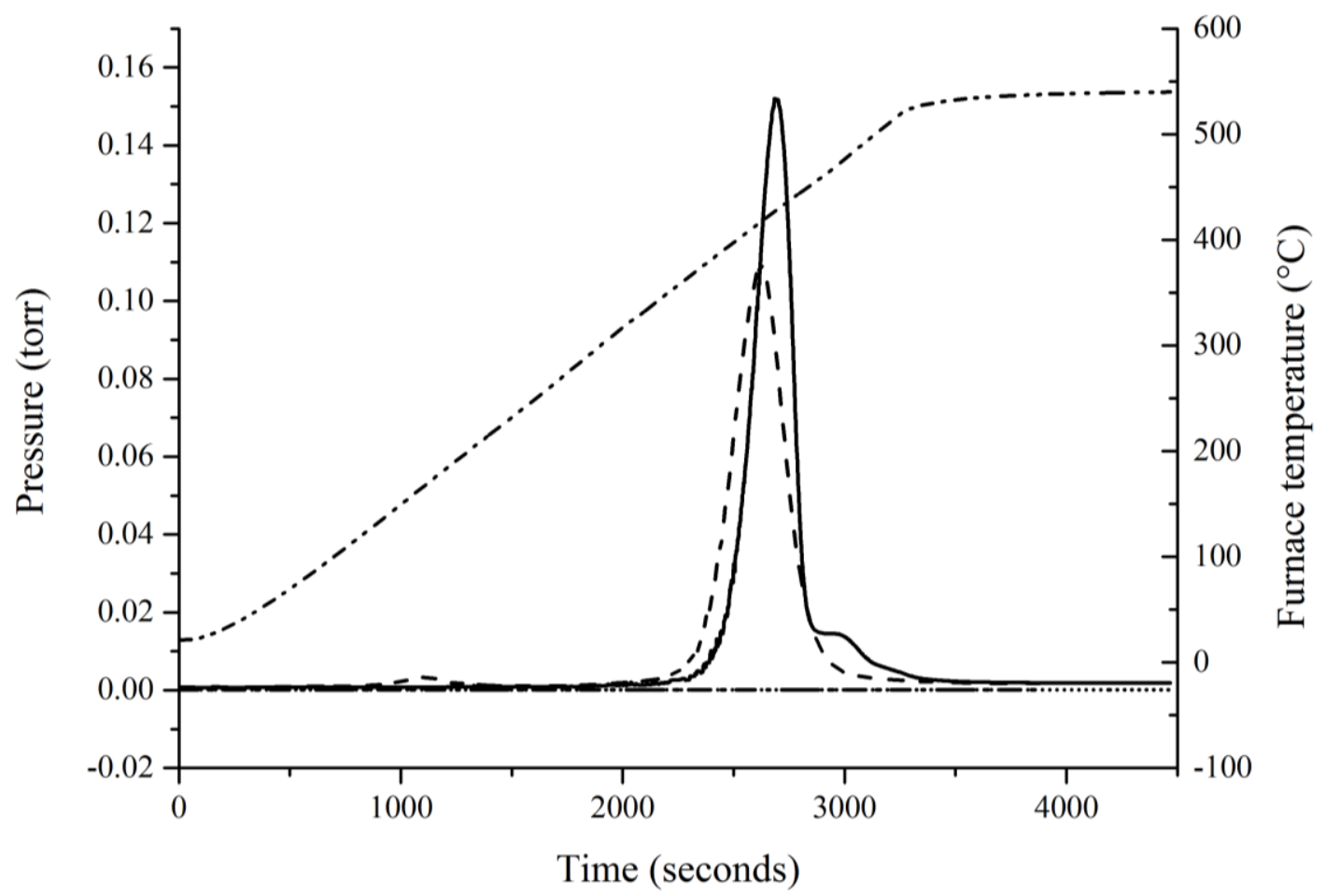

Figure 1: TVA degradation profile for polystyrene and poly(4-methylstyrene).

(- - -) Polystyrene products volatile at ambient temperature.

(. . .) Polystyrene products which do not condense at $-196^{\circ} \mathrm{C}$ (non-condensable volatiles).

(--) Poly(4-methylstyrene) products volatile at ambient temperature the solid line

(. . .) Poly(4-methylstyrene) condensable volatiles.

(. . . Sample temperature. 


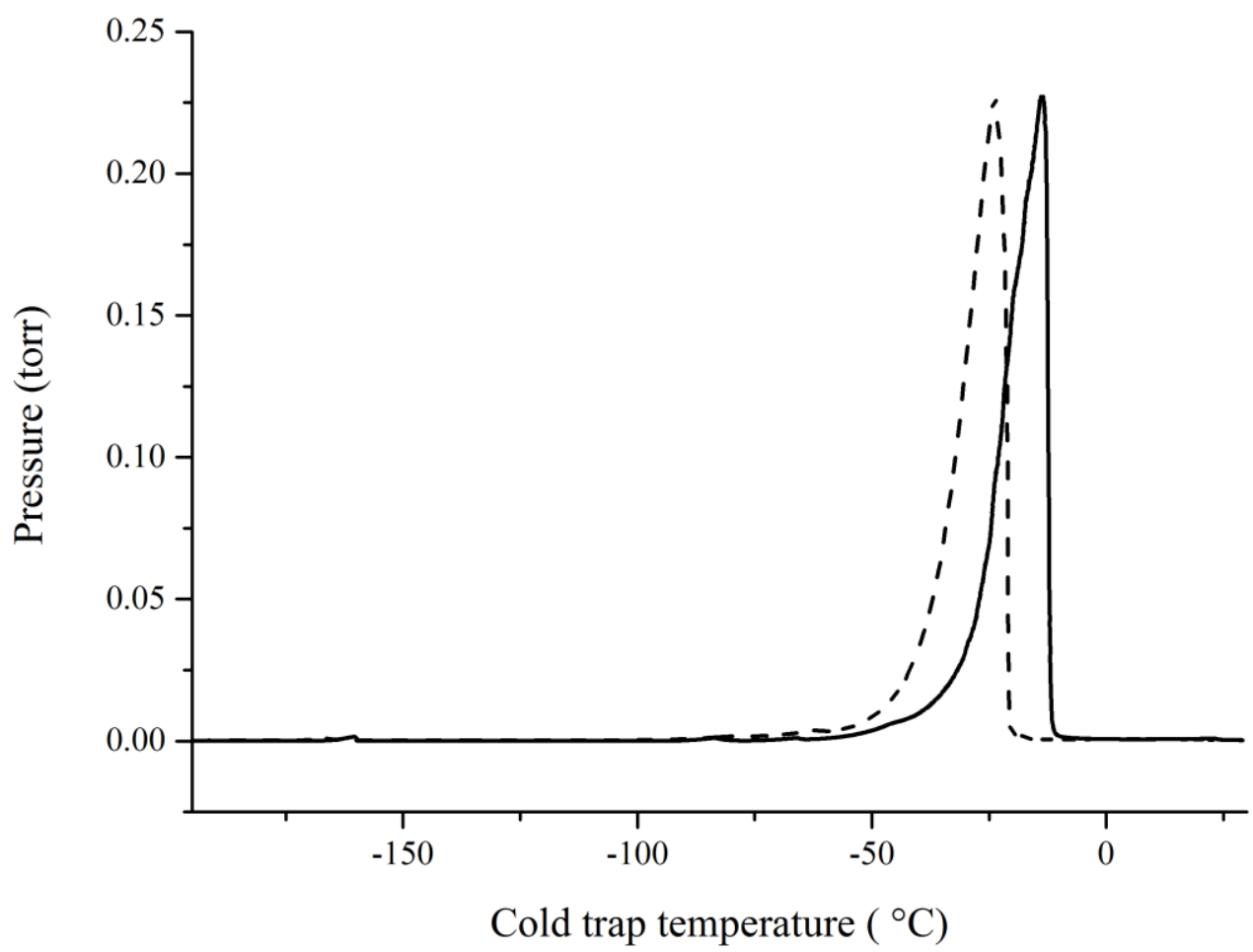

Figure 2: Sub-ambient distillation curves for polystyrene (dashed line) and poly(4-methylstyrene) (solid line).

The decomposition products were characterised using online mass spectrometry which identified the major products to be styrene and 4-methylstyrene (figure 3). 


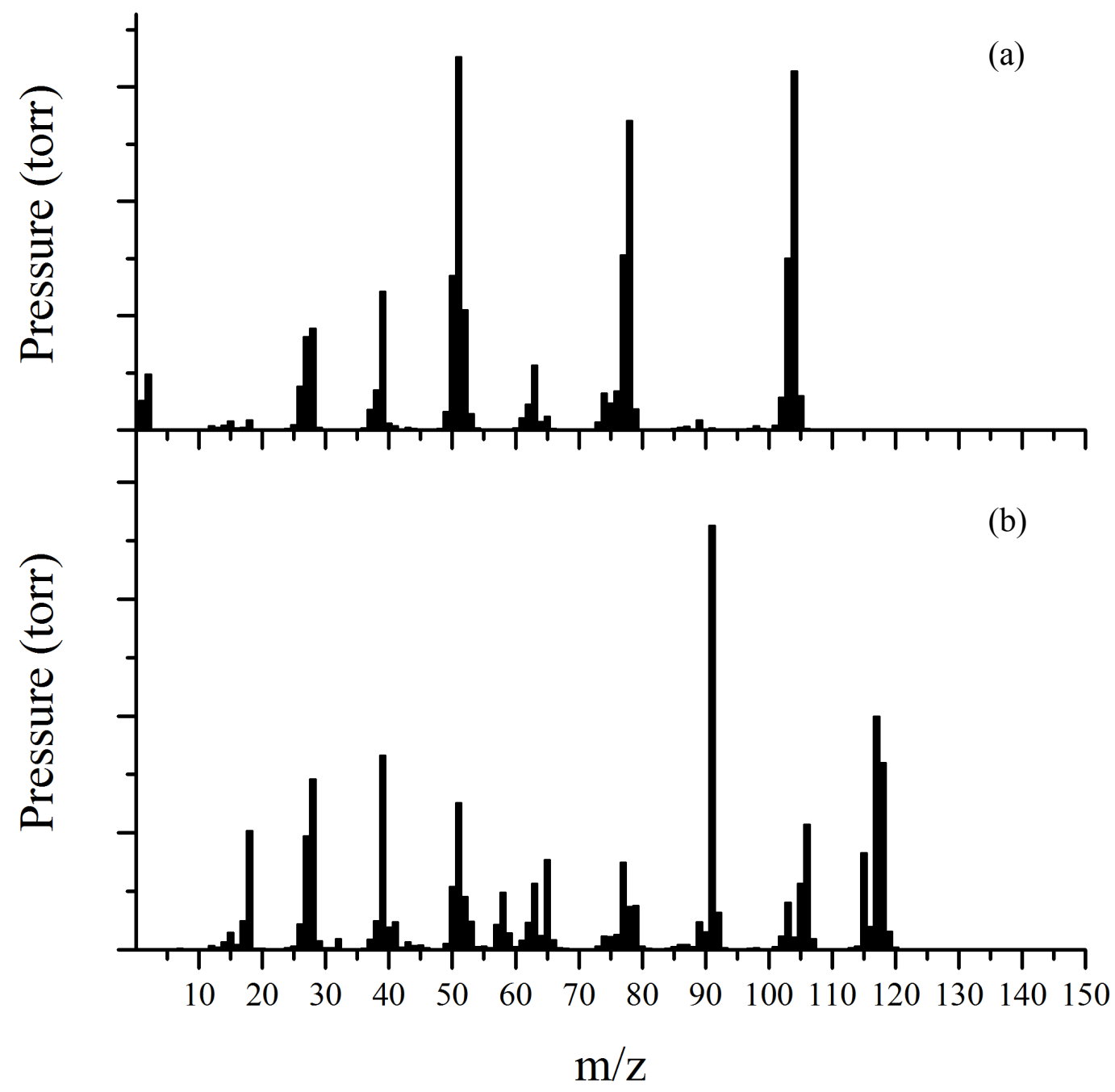

Figure 3: Mass spectrometry data obtained during sub-ambient distillation stage of TVA run. (a) Mass spectrum from polystyrene degradation collected from the single product peak present in the sub-ambient distillation which confirms the major product of styrene at $104 \mathrm{mlz}$; (b) Mass spectrum from poly(4-methylstyrene) degradation (b) collected from the single product peak present in the subambient distillation which confirms the major product of 4-methylstyrene at $118 \mathrm{mlz}$.

\section{$3.2 T G A$}

The TGA mass loss curves accompanied by the first derivative curves for polystyrene and poly(4-methylstyrene) are presented in figure 4. Upon initial inspection, it is apparent that for both polymers the onset temperature of degradation occurs at lower temperatures within an oxidative environment, showing that oxygen has, as expected, a destabilising effect. The TGA analysis of polystyrene under helium shows a single step degradation profile similar to that observed in TVA. For oxidative conditions there are shifts in temperature of the onset and peak degradation rate and the presence of a small second step associated with the burnoff of a small quantity $(\sim 2 \%)$ of oxidatively cross-linked material. The observed onset of 
degradation under non-oxidative conditions occurred at $386^{\circ} \mathrm{C}$, with the peak rate of degradation occurring at $427^{\circ} \mathrm{C}$ which is in good agreement with the previous TVA data. Under oxidative degradation conditions the onset temperature of degradation dropped to $316^{\circ} \mathrm{C}$ (reduction of $70^{\circ} \mathrm{C}$ ) and the peak rate of degradation dropping $63^{\circ}$ to $364^{\circ} \mathrm{C}$.

Whilst the non-oxidative profile of poly(4-methylstyrene) shows little variation from that observed for polystyrene, with the onset of degradation at $377^{\circ} \mathrm{C}$ and the peak rate of degradation occurring at $412^{\circ} \mathrm{C}$, when under an oxidative environment a more evident secondary degradation process (the burn-off of cross-linked material) is visible over the range $450-550^{\circ} \mathrm{C}$. The lowering of degradation onset was again observed but to a reduced extent, reflecting the competition between cross-linking and mass loss through depolymerisation. The first onset of degradation present in the oxidative curve occurred at $359^{\circ} \mathrm{C}$ (reduction of $18^{\circ} \mathrm{C}$ ) with the peak rate occurring at $395^{\circ} \mathrm{C}$ and the onset of burn-offoccurring at $508^{\circ} \mathrm{C}$ with a peak rate of degradation at $596^{\circ} \mathrm{C}$.

TGA analysis highlights that the thermal oxidative degradation of polystyrene and poly(4methylstyrene) are similar.Both are dominated by depolymerisation but both show evidence of oxidative cross-linking, with this bing much more apparent in poly(4-methylstyrene).
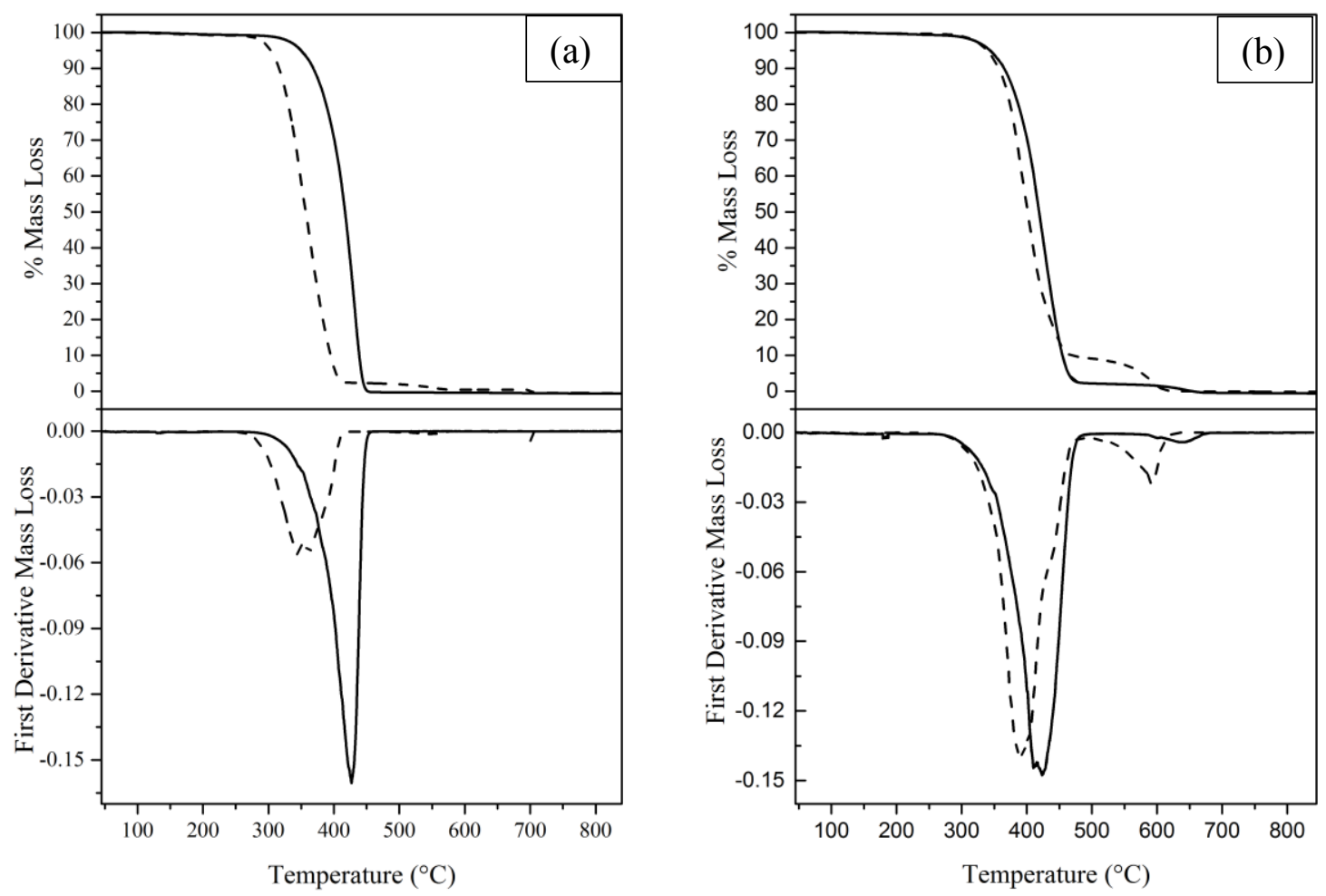
Figure 4: TGA mass loss curves (upper) and first derivative curves (lower) for polystyrene and poly(4-methylstyrene).

(a) polystyrene under argon (solid line) and under air (dashed line);

(b) poly(4-methylstyrene) under argon (solid line) and under air (dashed line) .

\subsection{Preparation and characterisation of pre-oxidised polymers}

\subsubsection{TGA of samples pre-oxidised in situ}

Further to the initial TGA characterisation (Section 3.2) a more sophisticated analysis involving in situ isothermal treatment polystyrene and poly(4-methylstyrene) was carried out. Two separate experiments for each polymer were performed: the initial step was isothermal heating at $230^{\circ} \mathrm{C}$ for 60 minutes, under either air or argon. Subsequently, the sample was cooled to $40^{\circ} \mathrm{C}$ and then analysed under an argon atmosphere at a ramp rate of $10^{\circ} \mathrm{C} \mathrm{min}^{-1}$ to $850^{\circ} \mathrm{C}$. The curves collected for these in-situ isothermal heating experiments are presented in figure 5 and data summarised in Table 2 and show that the pre-oxidation step induces mass loss behaviour upon subsequent heating in an inert atmosphere akin to that obtained under direct heating in an oxidative atmosphere. In particular, the oxidative pre-treatment of poly(4-methylstyrene) moves the initial step to higher temperatures and introduces the high temperature plateau whilst, in contrast, polystyrene is simply destabilised relative to untreated polymer in a manner identical to that observed for direct heating under air. What is interesting is that non-oxidative treatment also increases the temperature of the initial step for poly(4-methylstyrene) (the maximum rate of mass loss moves $\sim 40^{\circ} \mathrm{C}$ ) but does not induce the plateau. 

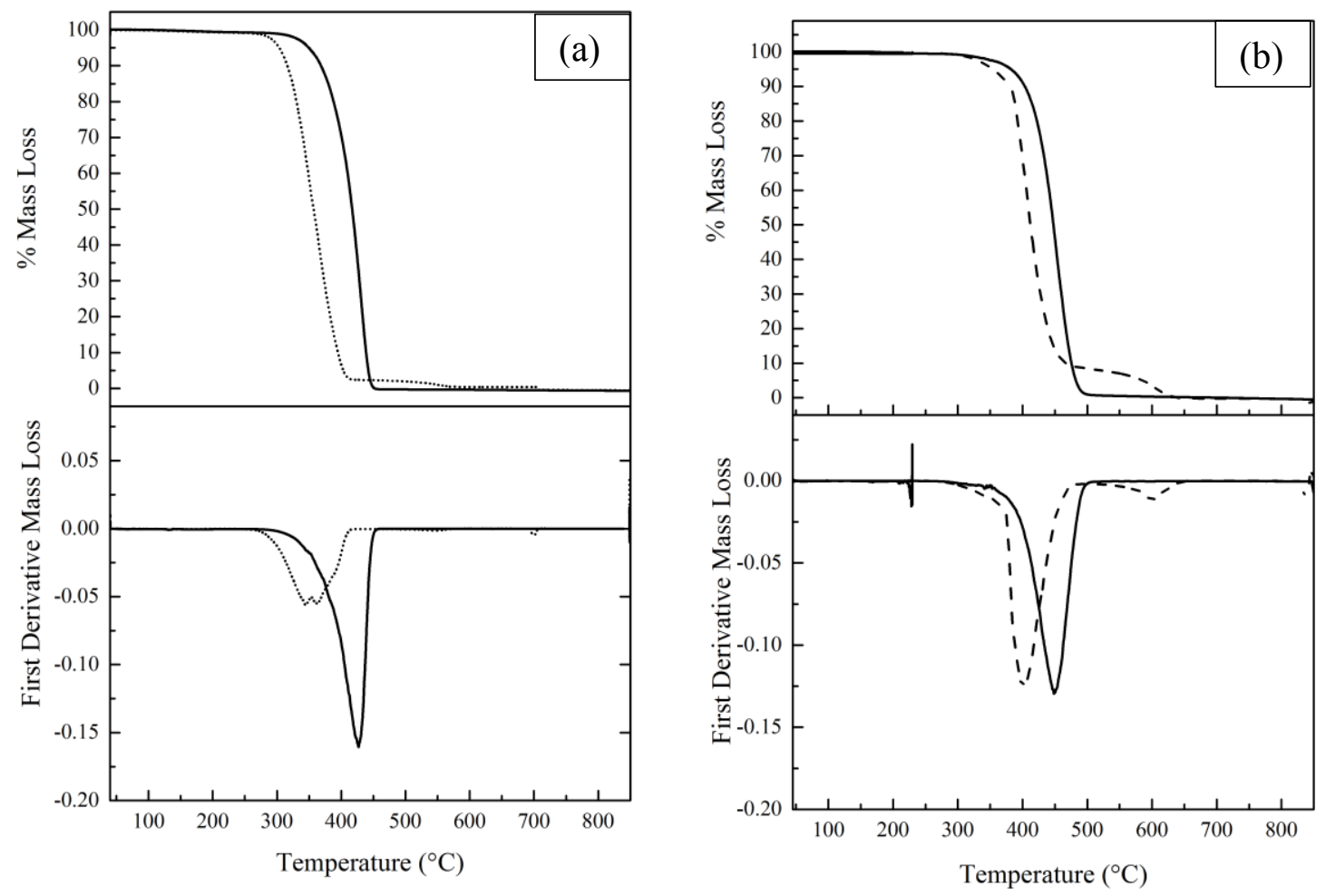

Figure 5: TGA mass loss curves (upper) and first derivative (curves) for in-situ pre-treated samples. (a) Polystyrene pre-heated isothermally under argon (solid line) and under air (dotted line). (b) Poly(4-methylstyrene) heated isothermally under argon (solid line) and under air (dashed line). 
Table 1: Collated TGA data for polystyrene, poly(4-methylstyrene) and in situ and ex situ pre-oxidised poly(4-methylstyrene)

\begin{tabular}{cccc}
\hline Sample/Atmosphere & Degradation Step & Peak Onset & Peak \\
\hline PS, untreated, argon & 1 & ${ }^{\circ} \mathbf{C}$ & ${ }^{\circ} \mathbf{C}$ \\
PS, untreated, air & 1 & 386 & 427 \\
\hline P4MS, untreated, argon & 1 & 316 & 364 \\
\hline P4MS, untreated, air & 1 & 377 & 412 \\
\hline PS, in-situ, argon & 2 & 359 & 395 \\
PS, in-situ, air & 1 & 508 & 596 \\
\hline P4MS, in-situ, argon & 1 & 386 & 431 \\
\hline P4MS, in-situ, air & 1 & 316 & 364 \\
\hline P4MS, ex-situ, & 1 & 394 & 451 \\
air, 230 ${ }^{\circ} \mathbf{C}$ & 2 & 383 & 410 \\
\hline P4MS, ex-situ, & 1 & 573 & 604 \\
air 250 ${ }^{\circ} \mathbf{C}$ & 2 & 352 & 433 \\
\hline P4MS, ex-situ, & 1 & 631 & 702 \\
\hline air 270 & 2 & 350 & 421 \\
\hline Po & 1 & 635 & 694 \\
\hline
\end{tabular}

$\mathrm{PS}=$ Polystyrene, $\mathrm{P} 4 \mathrm{MS}=$ Poly(4-methylstyrene)

\subsubsection{Pre-oxidation ex situ: gel content, TGA and structural characterisation}

To characterise the thermally more stable material observed in the TGA analysis of poly(4methylstyrene) larger samples were treated as outlined in Section 2.2. These experiments were carried out in duplicate for both polystyrene and poly(4-methylstyrene) on thin polymer films (for preparation see section 2.2). The temperatures were $230^{\circ} \mathrm{C}, 250^{\circ} \mathrm{C}$ and $270^{\circ} \mathrm{C}$ for 60 minutes under air.

\subsubsection{Gel Content}

Data for insoluble gel content for the treated polymers are shown in Table 2, from which it is clear that there is a significant degree of cross-linking occurring for poly(4-methylstyrene) but virtually none for polystyrene under these conditions 
Table 2: Gel contents of polymers isolated from ex-situ pre-oxidation experiments

\begin{tabular}{cccc}
\hline Polymer & $\begin{array}{c}\text { Temperature } \\
/{ }^{\circ} \mathbf{C}\end{array}$ & Run & $\begin{array}{c}\text { Gel Yield } \\
/ \%\end{array}$ \\
\hline \multirow{2}{*}{ Polystyrene } & & 1 & 0.5 \\
& 230 & 2 & 0.0 \\
Poly(4-methylstyrene) & & 1 & 8.8 \\
& & 2 & 8.7 \\
Polystyrene & 250 & 1 & 0.1 \\
& & 2 & 0.2 \\
Poly(4-methylstyrene) & & 1 & 8.6 \\
& & 2 & 8.6 \\
\hline \multirow{2}{*}{ Polystyrene } & & 1 & 0.0 \\
& 270 & 2 & 0.0 \\
Poly(4-methylstyrene) & & 1 & 8.6 \\
& & 2 & 8.3 \\
\hline
\end{tabular}

\subsubsection{TGA analysis}

TGA analyses of the insoluble gel material obtained from the oxidative pre-treatments of poly(4-methyl styrene) were undertaken. Samples were heated from $40^{\circ} \mathrm{C}$ to $850^{\circ} \mathrm{C}$ at $10^{\circ} \mathrm{C}$ $\min ^{-1}$ under argon, and the data are shown in figure 6 , from which it can be seen that all three pre-oxidised materials displayed the dual degradation profile that had been established in the previous TGA experiments, with the significance of the secondstep (burn-off of cross-linked material) increasing with pre-treatment temperature, although with little change in the temperature of the first step 


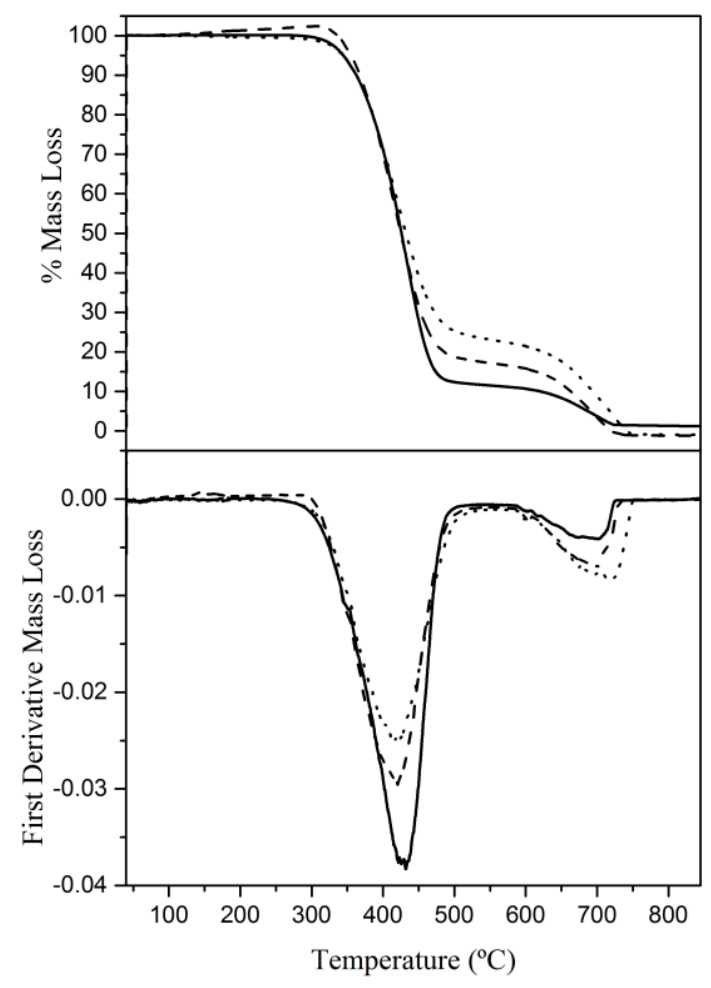

Figure 6: TGA mass loss curves (upper) and first derivative curves (lower) for the insoluble gel from poly (4-methylstyrene) pre-treated under oxidative conditions at $230^{\circ} \mathrm{C}$ (solid line), at $250^{\circ} \mathrm{C}$ (dashed line) and $270^{\circ} \mathrm{C}$ (dotted line).

\section{3..3.4 Structural characterisation of pre-oxidised materials}

The chemical changes occurring within poly(4-methylstyrene) during the ex-situ preoxidation process were characterised by elemental analysis, ATR-FTIR and NMR. Elemental analysis was carried out to determine the composition of the virgin polymer versus the gels from the three pre-oxidised materials. Table 3 displays the $\mathrm{C}, \mathrm{H}$ and $\mathrm{O}$ content along with the empirical formula of each polymer. An oxygen-free poly(4-methylstyrene) repeat unit gives an empirical formula of $\mathrm{C}_{9} \mathrm{H}_{11}$. The $230^{\circ} \mathrm{C}$ pre-oxidised material showed both a reduction in the carbon and hydrogen content, which corresponds to an increase in oxygen content with an empirical formula that corresponds to an oxygen content of one atom per four repeat units. When the treatment temperature was elevated to $250^{\circ} \mathrm{C}$ the empirical formula corresponds to an oxygen atom every two repeat units, and by the final treatment temperature of $270^{\circ} \mathrm{C}$ there is one oxygen atom per repeat unit. Elemental analysis was thus successful in clarifying that an increase in treatment temperature results in an increase in oxidation. 
Table 3: Elemental analysis of insoluble gels from ex-situ pre-oxidised poly(4-methylstyrene)

\section{Elements}

\begin{tabular}{ccccc}
\hline Sample & $\mathbf{C}$ & $\mathbf{H}$ & $\mathbf{O}$ (Calculated) & Empirical \\
& $/ \%$ & $/ \%$ & $\%$ & Formula \\
\hline Untreated & 90.28 & 8.66 & 1.06 & $\mathrm{C}_{114} \mathrm{H}_{131} \mathrm{O}_{1}$ \\
Air, $\mathbf{2 3 0}^{\circ} \mathbf{C}, \mathbf{6 0}$ mins & 88.41 & 8.39 & 3.2 & $\mathrm{C}_{37} \mathrm{H}_{42} \mathrm{O}_{1}$ \\
Air, $\mathbf{2 5 0}^{\circ} \mathbf{C} \mathbf{6 0}$ mins & 85.78 & 7.49 & 6.73 & $\mathrm{C}_{18} \mathrm{H}_{19} \mathrm{O}_{1}$ \\
Air, $\mathbf{2 7 0}^{\circ} \mathbf{C} \mathbf{6 0}$ mins & 80.62 & 7.23 & 12.15 & $\mathrm{C}_{9} \mathrm{H}_{10} \mathrm{O}_{1}$ \\
\hline
\end{tabular}

The ATR-FTIR spectra in figure 7 show clearly effect of the thermal oxidative pre-treatment on the polymer's functionality. Hydroxyl functionality was evident by the introduction of a broad peak within the range of $3100-3550 \mathrm{~cm}^{-1}$, with the peak intensity increasing as the oxidation temperature was increased. The aromatic ring C-H peaks above $3000 \mathrm{~cm}^{-1}$ appear marginally broadened, which is also evident in the aliphatic peaks situated below $3000 \mathrm{~cm}^{-1}$ and may indicate that the largest proportion of the oxidation is occurring on the aromatic pendent groups and along the polymer backbone. The carbonyl region also shows that oxidation has occurred. The non-treated polymer spectrum displayed a very small carbonyl peak at $1725 \mathrm{~cm}^{-1}$ which could possibly be attributed to an initiator end group such as benzoyl peroxide. However, upon thermal oxidative treatment there is a marked increase in the level of carbonyl functionality. The intensity of the carbonyl peak increased as the thermal oxidative treatment temperature was increased. The range $1740-1690 \mathrm{~cm}^{-1}$ in which the carbonyl peak is situated would suggest that there was more than one carbonyl moiety with the introduction of aldehyde and carboxylic acid groups both possible. As the methyl carbon occupies a benzylic position it makes it the most susceptible to oxidation. The next peak that shows an appreciable increase is situated at $1600-1580 \mathrm{~cm}^{-1}$ which corresponds to $\mathrm{C}=\mathrm{C}$ bonds, formation of this peak will be a combination of double bonds formed on the polymer backbone by hydrogen abstraction at the labile benzylic hydrogen and also unsaturated end groups formed by random chain scission during degradation.

Ring C-C vibration at $1510 \mathrm{~cm}^{-1}$ and the $\mathrm{C}-\mathrm{H}$ scissoring at $1450 \mathrm{~cm}^{-1}$ display a small broadening in line-shape. Visible growth of the shoulder peak at $1420 \mathrm{~cm}^{-1}$ supports the previous observation that carboxylic acid groups have been introduced during the degradation 
as this vibration is characteristic of $\mathrm{O}-\mathrm{H}$ bending. There will also be contributions of the $\mathrm{C}-\mathrm{H}$ in plane deformation that is present in the virgin material. The $\mathrm{C}-\mathrm{H}$ rocking vibration at 1380 $\mathrm{cm}^{-1}$ remains constant in all four materials suggesting the oxidation has occurred only at the methyl position. C-O stretching of the carboxylic acid now present within the oxidised materials was present at $1275 \mathrm{~cm}^{-1}$, which again mirrored increasing peak intensity with increasing temperature. At $1210 \mathrm{~cm}^{-1}$ a visible shoulder is observed which will have contributions from both the $\mathrm{C}-\mathrm{H}$ skeletal vibration of the non-degraded polymer and the $\mathrm{C}-\mathrm{C}$ stretch from the benzene to aldehyde carbon within the oxidised materials.

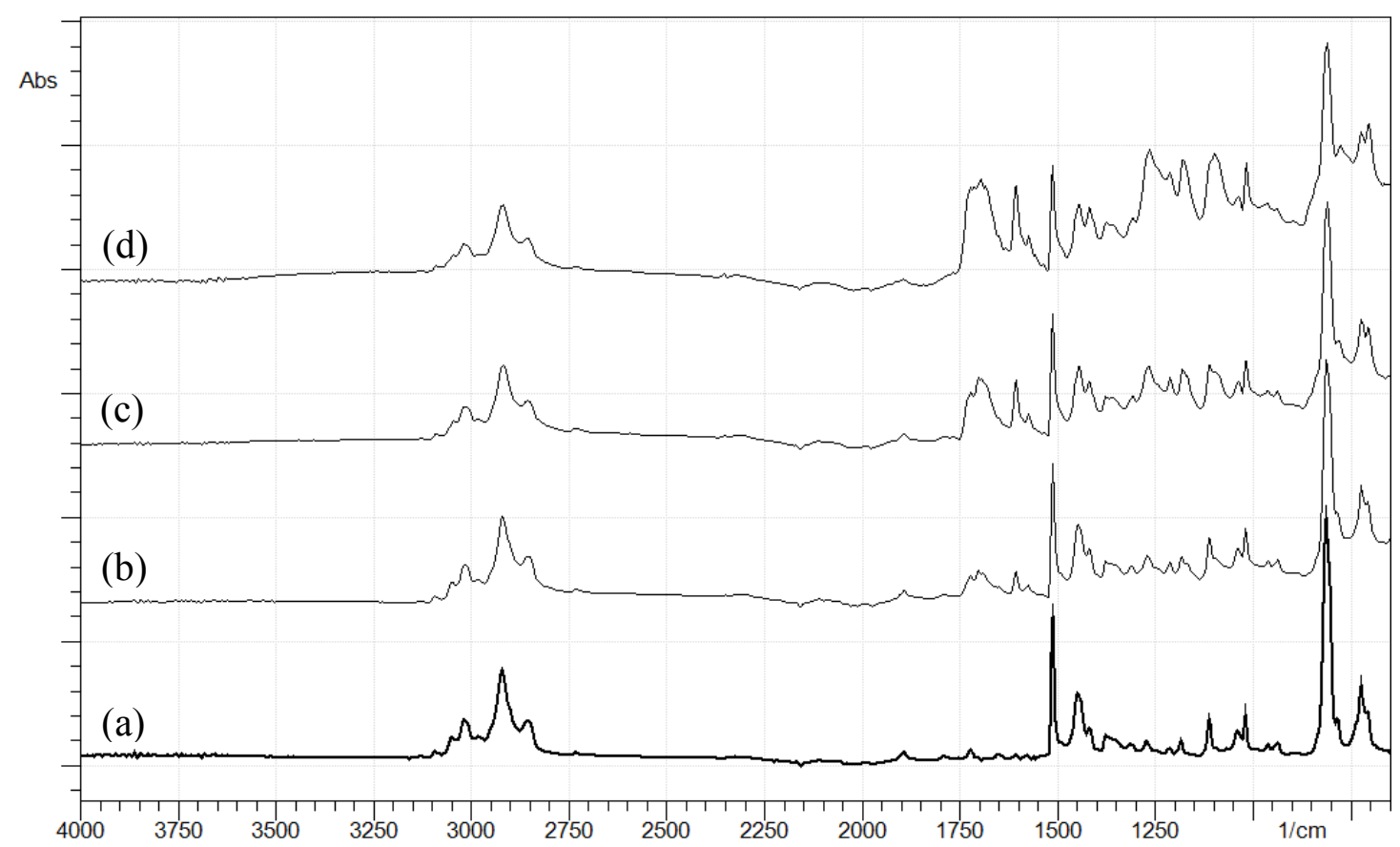

Figure 7: ATR-FTIR spectra of (a) poly(4-methylstyrene); (b) pre-oxidised material at $230^{\circ} \mathrm{C}$; (c) pre-oxidised material at $250^{\circ} \mathrm{C} ;$ (d) and pre-oxidised material at $270^{\circ} \mathrm{C}$. The plots are averages obtained from 5 sample positions of each material, with each individual spectrum containing 128 scans at $8 \mathrm{~cm}^{-1}$ resolution.

The contributing C-C vibration of the ring to aldehyde carbon is observed at $1190 \mathrm{~cm}^{-1}$, with this vibration inheriting a noticeable shoulder which is characteristic of the symmetric C-O stretch for an ether group. Accompanying this new vibration is the partnering anti-symmetric C-O ether stretch visible at $1075 \mathrm{~cm}^{-1}$, with the peak intensity increasing with each increase in temperature. The $\mathrm{C}-\mathrm{H}$ in plane bending vibration of poly(4-methylstyrene) occurs at 1100 $\mathrm{cm}^{-1}$ which was still visible within the $230^{\circ} \mathrm{C}$ and $250^{\circ} \mathrm{C}$ oxidised samples but the vibration is convoluted with the ether at the highest temperature of $270^{\circ} \mathrm{C}$. The twin peaks at $1050 \mathrm{~cm}^{-1}$ 
and $1025 \mathrm{~cm}^{-1}$ correspond to $\mathrm{C}-\mathrm{H}$ in plane deformation modes of the ring, supporting the theory of oxidative chemistry occurring at the ring methyl position preferentially. The doublet occurring at $950 \mathrm{~cm}^{-1}$ represents further ring $\mathrm{C}-\mathrm{H}$ in plane deformation modes which is present in all the materials, however, in each oxidised material an observed weak shoulder peak at $975 \mathrm{~cm}^{-1}$ was present corresponding to the $\mathrm{O}-\mathrm{H}$ bending vibration of the carboxylic acid group. The 1,4-disubstitution of the polymer is shown by the large absorbance peak at $800 \mathrm{~cm}^{-1}$ which corresponds to the $\mathrm{C}-\mathrm{H}$ out-of-plane deformation for two adjacent protons. A new peak that was not observed in the virgin material grows on the shoulder of this peak at $780 \mathrm{~cm}^{-1}$ and corresponds to the $\mathrm{C}-\mathrm{H}$ bands of a para substituted ring after oxidation. The final peak of the spectrum, a doublet at $725 \mathrm{~cm}^{-1}$ is representative of the $-\left(\mathrm{CH}_{2}\right)_{\mathrm{n}}$ - rocking vibration of the polymer backbone where $\mathrm{n}$ is equal to three or more carbons in a chain. The emergence of a peak which overlaps with this vibration corresponds with $\mathrm{C}=\mathrm{C}$ deformation, clarifying that the double bond formation occurs along the backbone. ATR-FTIR displayed the introduction of $\mathrm{C}=\mathrm{C}$ bonds, hydroxyl, aldehyde, carboxylic acid and ether functionalities. The identification of the ether groups would support the theory of oxidation introducing cross-links into the polymer matrix to form an insoluble and isolatable material.

The FTIR data is therefore consistent with oxidative cross-linking through the 4-methyl position. However, other mechanisms may operate. For example, abstraction at the tertiary backbone hydrogen would give a radical that could be delocalised to the methyl group giving a quinoid structure lowering the energy of activation for methyl hydrogen abstraction. Oxygen could add to this site with subsequent cross-linking as proposed, but also the quinoid structures or quinoids and unsaturated backbone sites could give Diels Alder condensation leading to aromatic thermally stable char. The presence of absorptions at about 1650 and $1250 \mathrm{~cm}^{-1}$ typical of intermediate charred material, well known to scientists studying coal formation, is consistent with this process.

NMR was used as a complementary technique to aid with the confirmation of the new functional groups observed previously in ATR-FTIR analysis. NMR analysis of the preoxidised samples was only possible by swelling the materials within $\mathrm{d}_{7}$-dimethylformamide to solvate the groups of interest. The oxidised materials that had a higher degree of crosslinking proved problematic to analyse using this approach as their swelling capability was far reduced making solvation of the groups more difficult. The soluble component of the 
oxidised materials was analysed separately to determine the functional groups that were present before cross-linking inhibited dissolution.

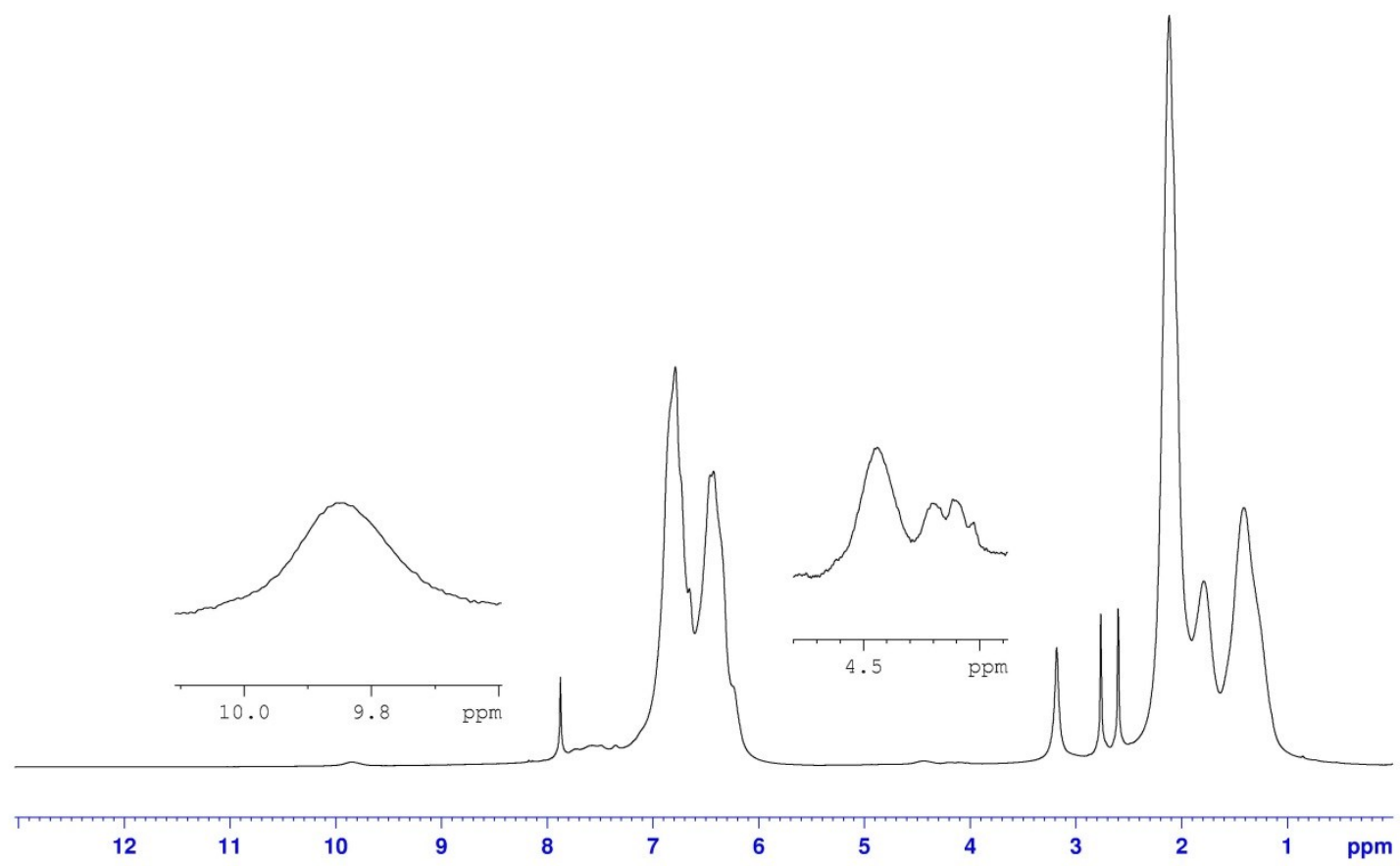

Figure 8: ${ }^{l} \mathrm{H}$ NMR spectrum of the ex-situ $230^{\circ} \mathrm{C}$ pre-oxidised poly(4-methylstyrene) gel swollen in dimethylformamide.

The observed broad peaks in the proton NMR spectrum of the ex-situ pre-oxidised sample prepared at $230^{\circ} \mathrm{C}$ (figure 8 ) are inherent of the atactic nature of the polymer and the variety of stereochemical environments occupied by each proton. Poly(4-methylstyrene) signals appear at $1.40 \mathrm{ppm}$ for the methylene hydrogen, methine hydrogen at $1.9 \mathrm{ppm}$ and the methyl hydrogen at $2.3 \mathrm{ppm}$. The aromatic protons of the pendant group have two shifts at $6.6 \mathrm{ppm}$ for the hydrogen meta to the methyl group and $6.9 \mathrm{ppm}$ for the hydrogen ortho to the methyl group. Within the spectrum obtained for the $230^{\circ} \mathrm{C}$ oxidised material the appearance of benzylic oxidation signals between 5.5 and $4.5 \mathrm{ppm}$ are evidence of methyl oxidation. The new peak at $4.6 \mathrm{ppm}$ represents the $\mathrm{CH}_{2}$ protons positioned either side of an ether cross-link. The new peak that has emerged at $9.90 \mathrm{ppm}$ is the $\mathrm{CH}$ of an aldehyde group formed at the methyl group of the polymer. Although no peak was observed for the carboxylic acid which can be common in low concentrations as the peak is typically broad and difficult to observe, 
evidence that carboxylic acid groups are present within the oxidised polymer can be inferred by the downfield shift of the aromatic protons ortho to the methyl group around $7.9 \mathrm{ppm}$.

At increased treatment temperatures it would be expected, based on what was observed by infrared analysis, to observe an increase in the occurrence of each functional group. As a result of the increased cross-linking the ability to generate spectra for the elevated treatment temperature proved problematic. The proton signals detected in the $230^{\circ} \mathrm{C}$ treatment were observed in the $250^{\circ} \mathrm{C}$ cross-linked polymer; however the spectrum was of lower quality due to and increased signal-to-noise. This was further evident in the $270^{\circ} \mathrm{C}$ treatment which was of low quality as a direct result of the poor swelling capability of the cross-linked material making solvent penetration to new oxidised groups insufficient. Even with this difficulty proton NMR was still able to confirm what was observed using infrared analysis.

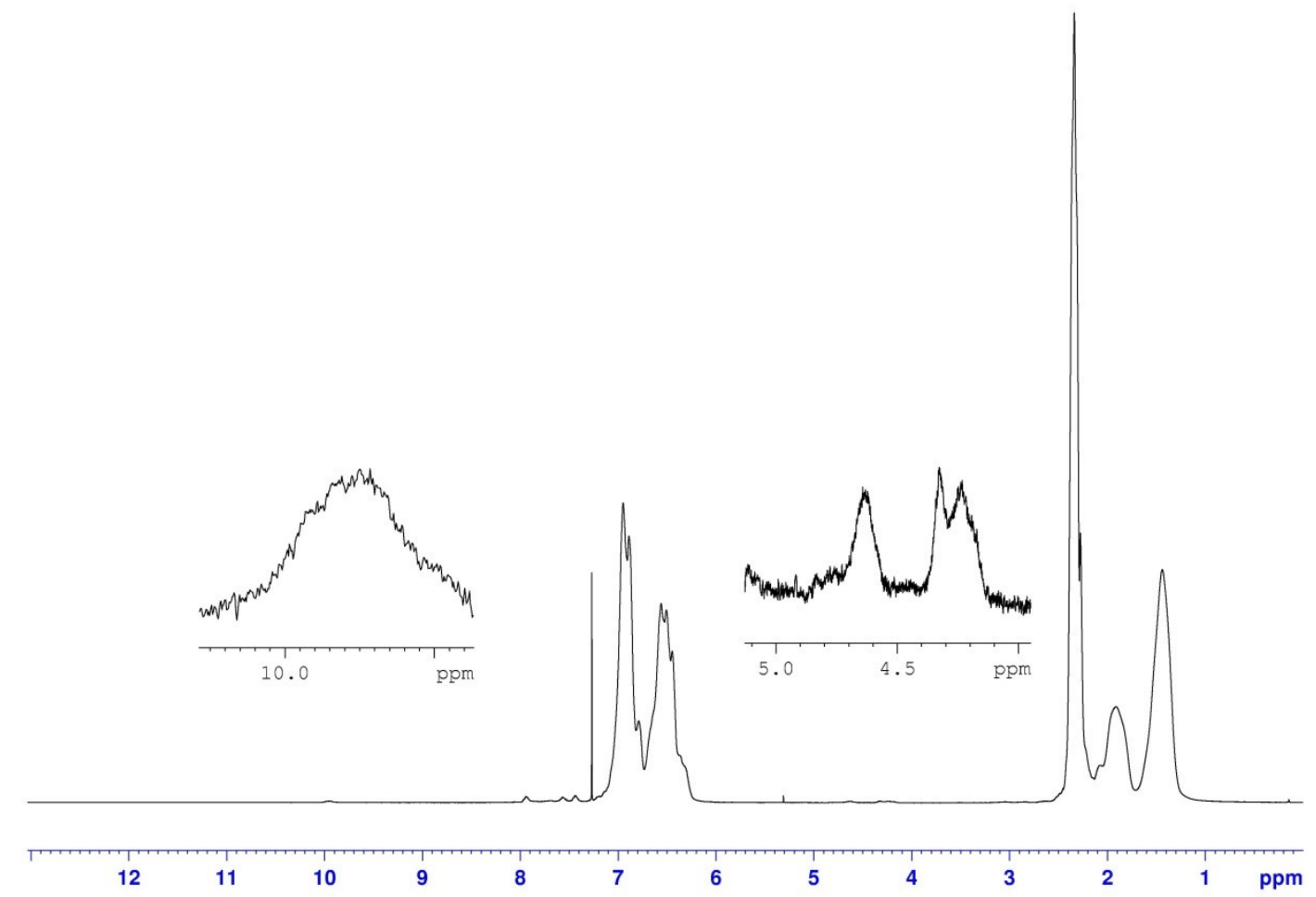

Figure 9: Soluble polymer component isolated after ex-situ pre-oxidative treatment at $230^{\circ} \mathrm{C}$. 
The NMR analysis of the soluble component obtained after treatment at $230^{\circ} \mathrm{C}$ is shown in Ffgure 9. The peak of the $\mathrm{CH}$ proton of an aldehyde group was observed at $9.9 \mathrm{ppm}$ and the downfield shift of the ortho protons were also visible at $7.6 \mathrm{ppm}$. The formation of carboxylic acid groups was confirmed from the downfield shift of the ortho proton to 7.9 ppm. Cross-linking was confirmed from the new peak at $4.6 \mathrm{ppm}$, which corresponds to the $\mathrm{CH}_{2}$ protons on the carbons either side of the bridging oxygen.

Chemical analysis in the form of elemental analysis, ATR-FTIR and NMR have displayed that upon heating within an oxidative environment it is possible to induce oxidation of poly(4-methylstyrene) in the absence of catalyst. Elemental analysis proved that the oxygen was incorporated within each treated material and that the oxygen content increased with increasing treatment temperature. ATR-FTIR plus NMR identified new oxidative groups such as aldehyde, carboxylic acid, hydroxyl and ether cross-links which all exclusively occurred at the para methyl position. The formation of $\mathrm{C}=\mathrm{C}$ bonds on the backbone of the polymer was also observed by ATR-FTIR, consistent with the predictions of Benson et al.. ${ }^{7}$

\subsection{Effect of oxidation on poly(4-methylstyrene) flammability}

Using chemical analysis techniques it was confirmed that oxidation of poly(4methylstyrene) occurs catalyst free between $230^{\circ} \mathrm{C}$ and $270^{\circ} \mathrm{C}$. Although aldehyde, carboxylic acid and hydroxyl groups are introduced, the most significant with respect to enhancement of the thermal stability of the polymer was cross-linking. The enhanced thermal stability of the cross-linked materials compared to the virgin polymer was confirmed using TGA. However to determine if the improved thermal stability of the oxidatively cross-linked materials corresponds to a reduction in flammability, PCFC was performed. Although the use of PCFC for flammability assessment is contentious, as it does not allow for effects such as melt flow, dripping, intumescence or gas-phase flame inhibition, PCFC is viable as a method for determining the combustion parameters of material when testing is required from milligram samples. ${ }^{24}$ Parameters measured using PCFC include the specific heat release rate under simulated fire conditions, the heat of combustion for the fuel gases, heat of combustion of solids and finally a derived quantity called the heat release rate. Sonnier et al. performed PCFC on variety of polymers with and without flame retardant. They found that PCFC was able to distinguish between them and that overall PCFC is a powerful tool for studying various aspects of flammability. ${ }^{28}$ Here, our data are the averages of three replicate determinations of each of the polymers. The heat release capacity (HRC) is used to relate the fire resistance of a polymer and is derived from dividing the maximum rate of heat release by the heating rate. ${ }^{29}$ Table 4: Pyrolysis combustion flow calorimetry data for poly(4-methylstyrene) and the gels isolated from the pre-oxidised materials. Data for polystyrene is shown for comparison. 


\begin{tabular}{|c|c|c|c|c|c|c|}
\hline & P4MS & PS & P4MS 230 & P4MS 250 & P4MS 270 & PS 270 \\
\hline HRC / J g ${ }^{-1} \mathrm{~K}^{-1}$ & 796 & 1174 & 608 & 473 & 468 & 571 \\
\hline Peak HRR / W g ${ }^{-1}$ & 789 & 1165 & 537 & 418 & 384 & 559 \\
\hline Total HR / kJ g-1 & 39 & 39 & 35 & 33 & 31 & 34 \\
\hline $\mathbf{T}_{\mathbf{p}} /{ }^{\circ} \mathbf{C}$ & 437 & 453 & 440 & 447 & 443 & 455 \\
\hline Heating Rate $/{ }^{\circ} \mathrm{C} \mathrm{s}^{-1}$ & 1 & 1 & 1 & 1 & 1 & 1 \\
\hline Fit Error: & 5 & 4 & 6 & 1 & 1 & 2 \\
\hline
\end{tabular}



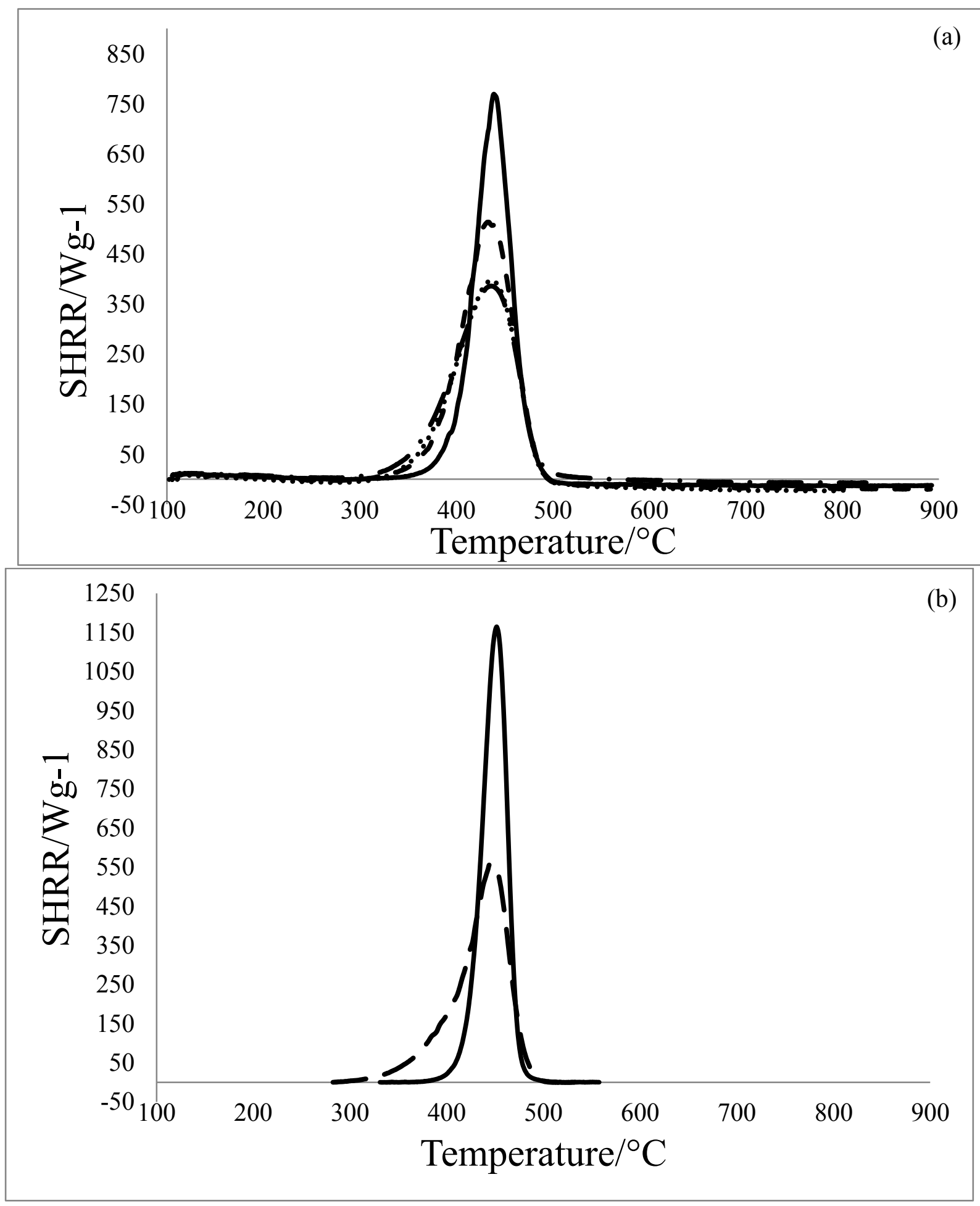

Figure 10: Specific heat release rate as a function of temperature displaying the reduced flammability of poly(4-methylstyrene) (upper) and (b) polystyrene (lower) compared to their preoxidised material. [Poly(4-methylstyrene) (solid line), $230^{\circ} \mathrm{C}$ pre-oxidised material (short dash line), $250^{\circ} \mathrm{C}$ pre-oxidised material (dotted line) and $270^{\circ} \mathrm{C}$ pre-oxidised material (long dash line). Polystyrene (solid line) and $270^{\circ} \mathrm{C}$ pre-oxidised material (long dash line)] 
HRC data obtained from the poly(4-methylstyrene) compared with the three oxidatively cross-linked materials displayed a significant decrease in the HRC. This decrease corresponds to a reduction in $\mathrm{HRC}$ from 796 to $468 \mathrm{~J} \mathrm{~g}^{-1} \mathrm{~K}^{-1}$ for the $270^{\circ} \mathrm{C}$ pre-oxidised material. Mirroring this encouraging result was the peak heat release rate (HRR) which also displayed the same trend. The reduced flammability was also confirmed by examining the total heat released with untreated poly(4-methylstyrene) releasing $39 \mathrm{~kJ} \mathrm{~g}^{-1}$ compared to the most cross-linked material obtained during the $270^{\circ} \mathrm{C}$ treatment which only released $31 \mathrm{~kJ} \mathrm{~g}^{-}$ 1. Figure 10 displays a plot of the specific heat release rate as a function of temperature for all of the polymers. The plot displays that as the amount of cross-linking within each oxidised material increases the flammability is reduced. Also presented within figure 10 is the data for polystyrene un-treated and pre-oxidised at $270^{\circ} \mathrm{C}$. Interestingly, whilst showing higher figures than poly(4-methylstyrene) for all the heat release data, polystyrene shows much the same \% drop in values subsequent to pre-oxidation, indicating that whilst there is virtually no insoluble gel observed some cross-linking (presumably through the tertiary hydrogen) must occur.

In practice, it must be remembered that the degradation chemistry in polymers during combustion is predominantly non-oxidative due to both the rapid reduction in the oxygen content on the combustion zone and the limited diffusion of oxygen into the polymer matrix. For example, Brauman et al. demonstated that under rapid heating conditions mimicking a fire scenario, polystyrene degraded in a manner similar to that under more conventional slowheating conditions in the absence of oxygen. ${ }^{30}$. We would anticipate, therefore, that oxidative cross-linking of 4-methyl styrene moieties would be restricted to the polymer surface although a cross-linked surface char of this sort would be expected to protect the underlying polymer by offering a thermal and diffusional barrier. Surface protection of this sort would be most relevant for the coating applications that poly(4-methyl styrene) is now entering.

\subsection{Conclusions}

Through thermal oxidative degradation it has been possible to induce cross-linking in poly(4methylstyrene) in the absence of catalyst. This thermal oxidative cross-linking was not observed for polystyrene under the same conditions. Chemical analysis displayed that oxidative treatment at elevated temperatures introduced aldehyde, carboxylic acid, hydroxyl and cross-linking ether functionalities, with all occurring at the benzylic methyl position. 
Cross-linking increased as the treatment temperature was increased which resulted in the materials isolated being thermally more stable. Thus from the pyrolysis combustion flow calorimetry data obtained we can confirm that the oxidative cross-links in poly(4methylstyrene) reduces the flammability of the polymer relative topolystyrene. That significant quantities of insoluble gel are not observed in polystyrene under the same conditions indicates that the cross-linking mechanism is specific to poly(4-methylstyrene) and cannot operate through the readily abstractable tertiary hydrogen alone. For polystyrene, cross-linking is restricted as oxidative dehydrogenation results in double bond formation at the tertiary position which results in the allylic bond becoming thermally weakened. Scission of this weakened bond results in chain end macro-radicals and subsequent propagation of unzipping. In poly(4-methylstyrene), the presence of the weakly electron-donating paramethyl group would marginally destabilise the tertiary radical, further reducing the likelihood of oxidative cross-linking through the tertiary hydrogen. In poly(4-methylstyrene), therefore, cross-linking via hydrogen abstraction from the para methyl position is more plausible, and is supported by the spectroscopic evidence. There is some evidence (the FTIR absorptions at 1650 and $1250 \mathrm{~cm}^{-1}$ ) that cross-linking via Diels Alder reactions of quinoid structures is occurring concurrently.

\section{Acknowledgements}

The authors would like to thank Dr P. L. Tang of Agilent technologies for access to the infrared instrumentation and assistance during data processing. 


\section{References}

(1) Wall, L. A.; Straus, S.; Flynn, J. H.; McIntyre, D.; Simha, R. The Journal of Physical Chemistry 1966, 70, 53.

(2) Gupta, M. C.; Nambiar, J. Colloid and Polymer Science 1983, 261, 709.

(3) Swistek, M.; Nguyen, G.; Nicole, D. Journal of Analytical and Applied Pyrolysis 1996, 37, 15.

(4) McNeill, I. C.; Zulfiqar, M.; Kousar, T. Polymer Degradation and Stability 1990, $28,131$.

(5) Madras, G.; Chung, G. Y.; Smith, J. M.; McCoy, B. J. Industrial \& Engineering Chemistry Research 1997, 36, 2019.

(6) McNeill, I. C.; Razumovskii, L. P.; Gol'dberg, V. M.; Zaikov, G. E. Polymer Degradation and Stability 1994, 45, 47.

(7) Benson, S. W.; Nangia, P. S. Accounts of Chemical Research 1979, 12, 223.

(8) Bolland, B.L.; Gee, G. Transactions of the Faraday Society, 1946, 42, 236.

(9) Bolland, B.L.; Gee, G. Transactions of the Faraday Society, 1946, 42, 244.

(10) Benson, S. W. Some Current Problems in Oxidation Kinetics National Bureau of Standards Special Publication, 1972.

(11) Boinon, B.; Abboud, W.; Bouras, A.; Ainad-Tabet, D. Polymer Degradation and Stability 1993, 42, 75.

(12) McNeill, I. C.; Ćoşkun, M. Polymer Degradation and Stability 1989, 23, 175.

(13) McNeill, I. C.; Ćoşkun, M. Polymer Degradation and Stability 1989, 25, 1.

(14) Bertini, F.; Audisio, G.; Kiji, J.; Fujita, M. Journal of Analytical and Applied Pyrolysis 2003, 68-69, 61.

(15) Brauman, S.K. Journal of Fire Retardant Chemistry, 1980, 7, 154.

(16) Wang, Z.; Jiang, D. D.; McKinney, M. A.; Wilkie, C. A. Polymer Degradation and Stability 1999, 64, 387.

(17) Yao, H.; McKinney, M. A.; Dick, C.; Liggat, J. J.; Snape, C. E.; Wilkie, C. A. Polymer Degradation and Stability 2001, 72, 399.

(18) Jang, B. N.; Costache, M.; Wilkie, C. A. Polymer 2005, 46, 10678.

(19) Jang, B. N.; Wilkie, C. A. Polymer 2005, 46, 2933.

(20) Liu, J.; Fu, M.; Jing, M.; Li, Q. Polymers for Advanced Technologies 2013, 24, 273.

(21) Wang, Z.; Du, X.; Yu, H.; Jiang, Z.; Liu, J.; Tang, T. Polymer 2009, 50, 5794. 
(22) Camino, G.; Bert, M.; Guyot, A.; Brossas, J.; Clouet, G. Fire Safety Journal 1980, $2,257$.

(23) Price, D.; Cunliffe, L. K.; Bullett, K. J.; Hull, T. R.; Milnes, G. J.; Ebdon, J. R.; Hunt, B. J.; Joseph, P. Polymer Degradation and Stability 2007, 92, 1101.

(24) McNeill, I. C. Journal of Polymer Science Part A-1: Polymer Chemistry 1966, 4, 2479.

(25) McNeill, I. C. European Polymer Journal 1967, 3, 409.

(26) McNeill, I. C. European Polymer Journal 1970, 6, 373.

(27) Lyon, R. E.; Walters, R. N. Journal of Analytical and Applied Pyrolysis 2004, $71,27$.

(28) Sonnier, R.; Otazaghine, B.; Ferry, L.; Lopez-Cuesta, J.-M. Combustion and Flame 2013, 160, 2182.

(29) Lyon, R.E.; Safronava, N.; Quintiere, J.G.; Stoliarov, S.I.; Walters, R.N.; Crowley, S. Fire and Materials, 2014, 38, 264. .

(30) Brauman, S.K.; Chen, I.J.; Matzinger, D.P. Journal of Polymer Science, Part A-1, Polymer Chemistry, 1983, 21, 1831. 
Supplementary Figure 1: Extent of colouration with increasing treatment temperature of poly(4-methylstyrene) for 60 minutes of treatment under oxidative conditions. From left to right poly(4-methylstyrene) without treatment white powder, $230^{\circ} \mathrm{C}$ treatment honey coloured material, $250^{\circ} \mathrm{C}$ treatment orange material and $270^{\circ} \mathrm{C}$ brown coloured material.

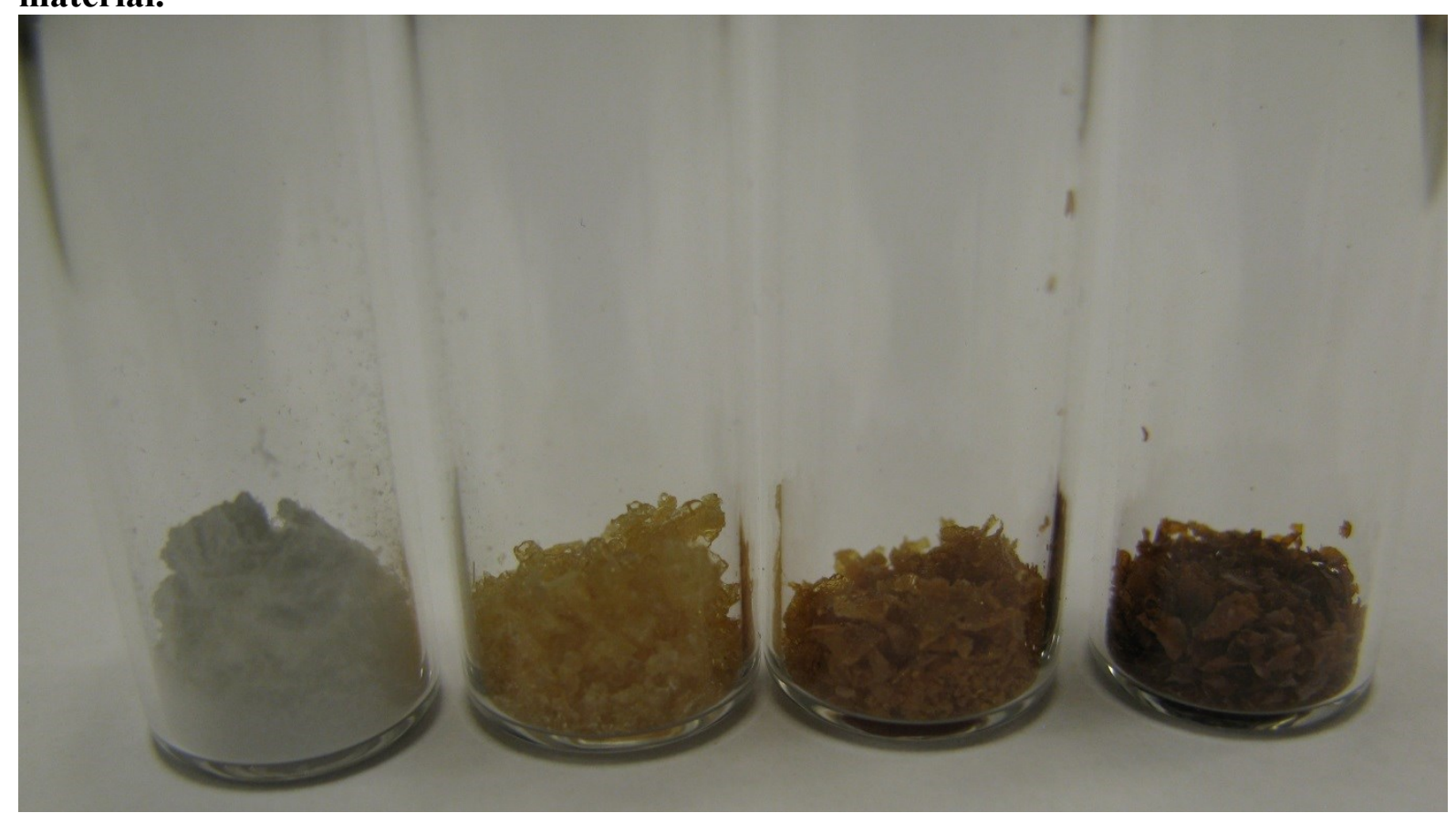

